\title{
CONSIDERAÇÕES SOBRE O INCONSCIENTE: MITO, SÍMBOLO E ARQUÉTIPO NA PSICOLOGIA ANALÍTICA
}

\author{
Considerations about the Uncounscious: Myth, Symbol and Archetype in Analitical Psychology
}

Consideraciones sobre el Inconsciente: Mito, Símbolo y Arquetipo en la Psicología Analítica

Carlos Augusto Serbena

\begin{abstract}
Resumo: Este artigo realiza uma discussão teórica entre C. G. Jung e outros autores visando relacionar e esclarecer aspectos dos conceitos de mito, símbolo e arquétipo. Partindo do conceito de inconsciente coletivo e de arquétipo da obra de Jung, mostra as duas formas de funcionamento da psique: racional e causal para o ego e imagética e analógica para o inconsciente. Assim, os arquétipos podem ser considerados como categorias da imaginação e se expressam de forma simbólica, exigindo uma abordagem compreensiva e qualitativa e exercendo função de mediação entre os opostos por meio de uma dinâmica redundante e repetitiva, mas aperfeiçoadora. Esse dinamismo aparece nos ritos, a repetição ao nível comportamental, e nos mitos, uma narrativa simbólica que marca o inicio do processo de racionalização dos símbolos. Se esse processo se aprofunda, o símbolo se conforma a signo, perdendo seu caráter vivencial e de mediar oposições. A excessiva valorização da racionalidade no pensamento moderno leva a desconsiderar o símbolo e, desse modo, o sujeito perde a possibilidade de mediar as oposições experienciadas na sua existência como entre si próprio e o mundo, sentindo sua vida vazia e sem significado.
\end{abstract}

Palavras-chave: Mito; Símbolo; Arquétipo; Sentido; Rito.

Abstract: This article conducts a theoretical discussion between C. G. Jung and other authors to relate and clarify aspects of the concepts of myth, symbol and archetype. On the concept of collective unconscious and archetype of the work of Jung, shows both forms of operation of the psyche: rational and causal to the ego and imaginal and analogic to the unconscious. Thus, the archetypes can be considered as categories of the imagination and are expressed in symbolic form, requiring a comprehensive, qualitative and acting role of mediation between the opposing dynamics through a redundant and repetitive, but improved. This dynamic appears in the ritual, the repetition behavioral level, and in myths, than are a symbolically narrative that mark the beginning of the process of rationalization of symbols. If this process is deepening, becomes the symbol sign and loses its experiential nature and ability to mediate conflicts. The excessive exploitation of rationality in modern thought leads to ignore the sign and thus the person loses the ability to mediate the conflicts experienced in its existence as between himself and the world, feeling their lives empty and meaningless.

Keywords: Myth; Symbol; Archetype; Meaning, Ritual.

Resumen: Este artículo realiza una discusión teórica entre C. G. Jung y otros autores pretendiendo relacionar y aclarar aspectos de los conceptos de mito, símbolo y arquetipo. Partiendo del concepto de inconsciente colectivo y de arquetipo de la obra de Jung, muestra las dos formas de funcionamiento de la psique: racional y causal para el ego e imagética y analógica para el inconsciente. De esa manera, los arquetipos pueden ser considerados como categorías de la imaginación y se expresan de forma simbólica, exigiendo un abordaje comprensivo y cualitativo y ejerciendo una función de mediación entre los opuestos por medio de una dinámica redundante y repetitiva, pero perfeccionadora. Esta dinámica aparece en los ritos, en la repetición en el nivel de comportamiento, y en los mitos, una narración simbólica que marca el inicio del proceso de racionalización de los símbolos. Si ese proceso se profundiza, el símbolo se transforma en signo, perdiendo su carácter vivencial y de mediar oposiciones. La valorización excesiva de la racionalidad en el pensamiento lleva a desconsiderar el símbolo y de esa manera, el sujeto pierde la posibilidad de mediar las oposiciones experimentadas en su existencia entre él y el mundo, sintiendo su vida vacía y sin significado. Palabras-clave: Mito; Símbolo; Arquetipo; Sentido; Rito

\section{Introdução}

O psiquiatra suíço C. G. Jung (1875-1961) foi um dos principais integrantes do movimento psicanalítico em sua fase inicial, sendo inclusive o primeiro presidente da associação internacional que reunia os psicanalistas. Divergiu de Freud ${ }^{1}$ inicialmente sobre o conceito de libi-

O relacionamento tumultuado entre Freud e Jung aparece nos volumes das correspondências completas e uma análise sucinta deste relacionamento, das divergências teóricas e influências recíprocas pode ser visto em Davis (2002). do, tomando-a de forma mais ampla que a conceituação sexual e, posteriormente, principalmente sobre a noção do inconsciente. O rompimento entre ambos foi selado na publicação do livro de Jung (1924/1986) "Símbolos da Transformação" no qual ele explicita suas diferenças teóricas com Freud. Basicamente, Jung amplia o conceito de libido, que passa a ser uma energia psíquica geral e não apenas de caráter sexual, como Freud a conceitua; a visão da psique e do inconsciente se modifica, pois ela passa a não ser "uma página em branco" no nascimento e o inconsciente amplia-se incluindo uma camada constituída 
de estruturas e imagens comuns a toda a humanidade (os arquétipos) que se manifestam nos sonhos, mitos, religiões e contos de fadas. Devido a isso, o método de análise de casos individuais modifica-se, incluindo-se comparações dos sonhos e fantasias com elementos da mitologia universal, além das associações pessoais.

Na sua concepção, o inconsciente possui uma amplitude muito maior que a consciência, sendo o ego apenas uma pequena parte da psique. Considera que a psique é constituída por elementos inconscientes originados de várias fontes, inicialmente do indivíduo até esferas mais coletivas e impessoais, pois o indivíduo está inserido em uma família, que faz parte de uma cultura ou etnia, que por sua vez é da espécie humana. Assim, os elementos de experiências inconscientes do indivíduo, apenas, formam o inconsciente pessoal; aquelas compartilhadas com a família ou a etnia, o inconsciente familiar ou étnico e, por último, os elementos inconscientes comuns a todos os indivíduos da espécie humana, o inconsciente coletivo (Jung, 1951/2000).

Devido a essa concepção ampliada de psique em Jung, pois inclui uma esfera coletiva e transcendente, ocorrem mudanças na concepção de consciência. Postula-se a existência da consciência do ego ou egóica que equivale à consciência no sentido do senso comum e da terminologia tradicional; e uma consciência ampliada, relativa à totalidade dos processos inconscientes e arquetípicos. Isso ocorre porque o inconsciente possui uma autonomia em relação ao ego, opera com muitas percepções que nem alcançam a consciência egóica e possui certas estruturas de imagens e comportamentos, os arquétipos, relativos a determinadas situações típicas e que funcionam como uma espécie de sabedoria instintiva e automática (Jung, 1924/1986; Whitmont, 1991).

Isto é importante porque a consciência egóica opera principalmente pelo raciocínio causal e lógico, mas a consciência ampliada do inconsciente funciona por meio de analogias, associações e semelhança, sendo essencialmente imagética. Assim, o relacionamento entre o consciente e o inconsciente opera principalmente por meio da imagem e da imaginação. Jung conceitua que a psique opera basicamente de duas formas diferentes, mas complementares: pelo inconsciente por meio da analogia e pela consciência por meio da lógica ou raciocínio analítico, assim o pensamento analógico é a forma do inconsciente operar. Este modo é visto nos sonhos, nas fantasias, no pensamento mítico.

Este pensamento não requer esforço, afasta-se da realidade para fantasias do passado e do futuro. Aqui termina o pensamento em forma de linguagem, imagem segue imagem, sensação segue sensação (...) trabalha sem esforço, espontaneamente, com conteúdos encontrados prontos e é dirigido por motivos inconscientes (...) afasta-se da realidade, liberta tendências subjetivas e é improdutivo em relação à adaptação (Jung, 1986, p. 16).
É um engano interpretar os produtos do pensamento analógico (sonhos, imagens, fantasias, mitos) dentro do campo da lógica analítica e linear, pois os critérios de verdade são diferentes, assim como sua estrutura e discurso. Se isso acontece, ocorre então a desvalorização dos símbolos, de sua função e introduz-se uma fonte de desequilíbrio na psique, pois eles fazem a conexão entre a consciência e o inconsciente.

A consciência é vista como menor que o inconsciente, estando inserida dentro da psique. O próprio conceito de inconsciente, como todos os fenômenos psíquicos desconhecidos da consciência, remete à sua amplitude desconhecida. O ser humano está cindido por natureza, entre consciente e inconsciente, entre uma realidade externa e objetiva e uma realidade interna e subjetiva. O pensamento analítico corresponderia a um direcionamento para a realidade externa e o pensamento analógico para a realidade interna.

Isso é claramente expresso na forma do sonho, sendo todo ele simbólico, como uma fábula da existência do sonhador e operando por meio de analogias. O inconsciente se manifesta simbolicamente e a consciência (ou ego) para acessar o seu inconsciente deve interpretar a mensagem que é expressa simbolicamente. A desvalorização da linguagem simbólica implica na desvalorização do inconsciente e da realidade subjetiva da psique (Jung, 1927/1985a).

É importante salientar que, segundo Jung (1949/1991), o símbolo é a melhor expressão possível de algo relativamente desconhecido, pois ele representa por imagens, experiências e vivências que incluem aspectos conscientes e inconscientes, isto é, desconhecidas da consciência. Como tal, o símbolo participa e existe sob a forma vivencial e experiencial, sendo impossível de ter seu significado esgotado ou determinado, possibilitando estabelecer múltiplas relações e analogias. Se um símbolo perde seu caráter "mágico", isto é, de atrair a atenção psíquica, pode-se dizer que não é mais um símbolo. A utilização excessiva do símbolo tende a reduzi-lo a indicador de um conceito ou de uma realidade material e este indicador não opera mais como símbolo e sim como signo. A degradação do símbolo em signo tem como exemplo os manuais do sonho que trazem guias e significados para cada figura ou imagem que aparece. Esta degradação implica em um empobrecimento da psique do indivíduo, pois reduz a multivocidade do símbolo na univocidade do signo, ou seja, a riqueza simbólica é reduzida a uma representação unívoca. Se algo é ou não símbolo, vai depender do ponto de vista e da atitude do indivíduo que contempla.

O símbolo pode realizar a mediação entre as diversas antinomias e oposições do sujeito, materializadas em uma oposição e relação entre o consciente e o inconsciente. Esta oposição provoca uma atividade inconsciente que se manifesta de forma simbólica com uma função de compensação desta oposição. Assim, o símbolo tem uma função de equilíbrio da psique como um todo. 
Entretanto, ele é criativo, pois o símbolo que surge deste dinamismo pode conter ou ser um fundamento que unifica os opostos (Jung, 1949/1991, §903). Deste modo, ele "esclarece a libido inconsciente pelo 'sentido' consciente que lhe dá, mas lastreando a consciência através da energia psíquica que veicula a imagem” (Durand, 1998, p. 63). Entretanto, esta mediação apenas ocorre quando há uma atitude participativa e receptiva por parte do indivíduo que deste modo permite a atuação da "função transcendente" do símbolo.

Sendo oriundos de estruturas arquetípicas, os símbolos representam situações e temas típicos e recorrentes da existência humana, tal como o nascimento, a morte, o casamento e a luta pela sobrevivência entre tantos outros e, deste modo, possuem uma constância de temas e significados, pois o arquétipo é uma estrutura do inconsciente, uma constante antropológica, como o denomina Maffesoli $(2003,2004)$. O inconsciente possui, então, uma parte pessoal que se refere às experiências pessoais do sujeito e uma parte impessoal composta pelos arquétipos, denominada de inconsciente coletivo. Ele

(...) parece se constituir de motivos mitológicos ou imagens primordiais, razão pela qual os mitos de todas as nações são seus reais representantes. De fato, a mitologia como um todo poderia ser tomada como uma espécie de projeção do inconsciente coletivo (...). Portanto, podemos estudar o inconsciente coletivo de duas maneiras: ou na mitologia ou na análise pessoal (Jung, 1924/1986, §325).

Os arquétipos são "estruturas básicas e universais $d a$ psique, os padrões formais de seus modos de relação são padrões arquetípicos" (Hillman, 1992, p. 22). O arquétipo pode ser utilizado como elemento ou base conceitual para compreender e explorar todos os tipos de experiências nas quais a função criativa da imaginação esteja presente, isto é, imaginais. Isto ocorre devido ao fato do arquétipo manifestar-se ou atuar simultaneamente em vários níveis ou estratos; como imagem, como padrão de percepção ou filtro da realidade e como um afeto ou impulso. Por exemplo, se o padrão arquetípico materno está constelado na psique, há a imagem da mãe, existindo então uma vontade ou impulso para comportamentos e atitudes de cuidado a outras pessoas e, desse modo, uma tendência a perceber o mundo sob a ótica do cuidado.

Existem vários arquétipos na mente humana, relacionados principalmente a situações típicas da existência humana: nascimento, morte, casamento, doenças e outros (Jung, 1950/1988). Jung levanta a hipótese de que eles se constituíram pela repetição do tema por várias gerações. O arquétipo não é acessível diretamente, mas apenas por suas manifestações: biológica, em padrões de comportamento, e psíquica, em imagens, representações e produções humanas formando um substrato comum à humanidade.
Este substrato comum é denominado inconsciente coletivo ou psique objetiva, pois sua existência é independente do ego e da subjetividade de cada indivíduo. Ele se formou pela repetição de comportamentos frente a determinadas situações semelhantes entre si ao longo das diversas gerações e durante a formação do homo sapiens, tornando-se um fundo psíquico comum à humanidade. $\mathrm{O}$ inconsciente coletivo e os arquétipos seriam os depositários deste repertório comportamental acumulado, porém não são os comportamentos, mas estruturas ou padrões de comportamento. Eles fazem parte da natureza humana universal, independente do tempo e das culturas.

A psique objetiva se manifesta essencialmente por imagens, emoções e impulsos. A expressão do inconsciente realiza-se de maneira não racional e pré-lógica. As relações entre as imagens e a realidade não são de causa e efeito, mas de similaridade e contiguidade, a lógica que prevalece é analógica. Desse modo e colocando que o inconsciente opera por analogia e imagens, "estas imagens devem ser consideradas como se apresentassem descrições de nós mesmos, ou de nossas situações inconscientes, na forma de analogias ou parábolas" (Whitmont, 1991, p. 35).

A Psicologia Analítica considera que a energia psíquica por detrás das imagens e símbolos é denominada libido, que na realidade é apenas uma metáfora ou um construto operacional para possibilitar um entendimento dos processos psíquicos. Desse modo, o termo "libido" resume fundamentalmente o laço afetivo entre o sujeito e um objeto fora do mesmo, indicando apenas a motivação ou inclinação desse sujeito em direção a este objeto. Operacionalmente, a libido pode ser descrita em dois aspectos complementares, o regressivo e o progressivo. O aspecto regressivo é orientado para dentro do próprio sujeito, suas fantasias, memória e sua história pregressa e o aspecto progressivo orienta-se para fora do sujeito, para os objetos externos, para os projetos e o tempo futuro (Jung, 1957/1985c).

Estes aspectos devem ser relativizados, pois o ego seria apenas a parte da psique responsável pela intermediação entre o mundo externo e a realidade interna. A realidade interna consiste de vários níveis, conforme já explicitado. Ela inicia-se pelo ego, pelo inconsciente pessoal, e estruturas inconscientes cada vez mais coletivas (família, etnia e humanidade). No aspecto regressivo, a percepção do símbolo passaria, então, inicialmente por um determinante pessoal, até significados cada vez mais coletivos e cada vez mais carregados de energia psíquica (motivação), até chegar ao inconsciente coletivo.

No aspecto progressivo a energia psíquica se dirige para fora, para o objeto externo. O objetivo é modificar a realidade externa, cultural ou material. A energia não segue um fluxo livre, mas segue uma finalidade de desenvolvimento mais amplo que apenas os objetivos do ego, mas visando integrar o consciente com o inconsciente. 
Pode-se observar um padrão na atuação da psique que corresponde a um movimento em direção à constituição de uma totalidade que abrange tanto o inconsciente quanto o consciente, ultrapassando a separação entre o ego e o inconsciente. Inclusive a relação entre a libido e os seus processos regressivos, isto é, o movimento da libido em direção aos objetos internos da psique, e progressivo, direcionamento da libido a objetos externos da psique, estão submetidos a esta busca da totalidade. Ela envolve tanto a transformação da atitude do ego (regressão) como a realização de tarefas no mundo externo (progressão). Este processo implica em uma transformação dos símbolos envolvidos; aqueles que inicialmente tinham significados individuais ou específicos passam a adquirir uma conotação mais ampla, ligando o indivíduo a uma totalidade cada vez maior como com a família, a etnia e o cosmos (Jung, 1954/1985b).

Na psique há o predomínio das imagens e os arquétipos podem ser considerados como categorias da imaginação, isto é, "no domínio da mente o instinto [arquétipo] é percebido como imagens, no domínio do comportamento, as imagens são desempenhadas como instinto. $O$ comportamento é sempre a encenação de uma fantasia" (Hillman, 1981, p. 197). O arquétipo deve ser pensado associado a padrões de imagens e de comportamentos, pois a imagem sem comportamento é vazia e sem sentido e o comportamento sem imagem é cego. Em termos teóricos, o correto é distinguir arquétipo de imagem arquetípica, pois o arquétipo em si é irrepresentável e aparece à psique sob a forma de uma imagem arquetípica. Entretanto costuma-se utilizar os dois termos indistintamente, mas deve estar clara esta distinção.

A abordagem destas categorias de imaginação, arquétipos ou imagens arquetípicas pede, não um levantamento empírico, mas uma "compreensão" da personalidade do sujeito a partir da vivência do mesmo, assim o termo "compreensão" está "implícito em todos os demais e situa a abordagem de Jung mais da tradição das psicologias da compreensão (Dilthey, Nietzsche, Jaspers) do que as psicologias que são explicatórias, descritivas" (Hillman, 1981, p. 193).

Os arquétipos também, tal como as situações, sentimentos e representações dos indivíduos, não estão separados rigidamente, existindo sempre a possibilidade de relação entre os símbolos, pois eles se interpenetram. Circulando ao longo dos temas, expressando, equilibrando e unificando os contrários, eles são sempre pluridimensionais, bipolares e ligados com a experiência totalizante possibilitada pela função transcendente e seu dinamismo integrador (Chevalier \& Gheerbrant, 1989, p. $\mathrm{XXV}$ ). Esse aspecto fica mais saliente porque os arquétipos não possuem conteúdo pré-determinado, atuando como padrões estruturais na mente humana que devem ser preenchidos com conteúdos da experiência individual do sujeito, a qual é social, cultural e historicamente localizada. Assim:
(...) eles [os arquétipos] só são determinados em sua forma e assim mesmo em grau limitado. Uma imagem primordial [arquétipo] só tem conteúdo determinado a partir do momento em que se torna consciente e é, portanto, preenchida pelo material da experiência consciente (Jung, 1961/1987, p. 352).

Esse conceito foi elaborado por Jung a partir da observação de muitos temas repetidos em mitologias, contos de fada, literatura universal e nos sonhos e fantasias de seus pacientes. Ele observou que as imagens que apareciam se relacionavam principalmente com situações comuns da existência humana tais como o nascimento, a iniciação social, o relacionamento sexual e afetivo e perdas, entre outros; existindo assim tantos arquétipos quantas são as situações típicas da existência humana e formando substrato psíquico comum a toda humanidade.

Ele é um conceito limite, pois não é acessível diretamente, mas apenas por suas manifestações em padrões de comportamento, em imagens, representações e produções humanas que são semelhantes e, desse modo, o conjunto dos arquétipos forma um substrato comum à humanidade denominado inconsciente coletivo ou psique objetiva. Essa última denominação mostra que a sua existência é independente do ego e da subjetividade de cada indivíduo manifestando-se essencialmente por imagens, emoções e afetos, de maneira não racional e pré-lógica, por meio de relações de similaridade e de contiguidade, com lógica analógica e não de causa e efeito. Assim, há na psique um padrão atuante e que corresponde a uma totalidade que abrange tanto o inconsciente quanto o consciente. Ele envolve tanto a transformação da atitude do ego (regressão) como a realização de tarefas no mundo externo (progressão). Este processo implica em uma transformação dos símbolos envolvidos, onde inicialmente tinham significados individuais ou específicos e passam a adquirir uma conotação mais ampla, relacionando o indivíduo a uma totalidade cada vez maior: família, etnia e cosmos (Jung, 1950/1988).

Este dinamismo ocorre pela repetição e redundância da vivência do símbolo e da sua expressão. Uma vez que seu significado é inesgotável e irrepresentável de forma lógica, o esclarecimento e a construção do sentido ou significado do símbolo ocorrem pela circulação ao redor de um centro, com redundância e repetições cada vez mais aproximadas e carregadas de significado, sendo comparável a um movimento em espiral. Deste modo, "o conjunto de todos os símbolos sobre um tema esclarece um símbolo, uns através dos outros” (Durand, 1998, p. 17).

Esta "redundância aperfeiçoadora" socialmente é visível principalmente nos rituais e nos mitos, pois os rituais são a atuação concreta ou expressão comportamental da dinâmica dos símbolos e arquétipos por meio da repetição de comportamentos e gestos e os mitos são a expressão discursiva na forma oral ou escrita da redundância das relações linguísticas e lógicas entre idéias e imagens 
significativas ou simbólicas (Durand, 1998). Observa-se que o discurso metafórico dos mitos é a linguagem fundamental dos arquétipos (Hillman, 1992, p. 23).

Deste modo, o símbolo e o seu dinamismo possuem várias funções. Inicialmente exploratória, investigando e exprimindo "o sentido da aventura espiritual dos homens, lançados através do espaço-tempo" (Chevalier \& Gheerbrant, 1989, p. XXVIII), representando e exprimindo o mundo percebido e vivido pelo sujeito em sua totalidade psíquica consciente e inconsciente e também substituindo conteúdos e vivências afetivas impossibilitadas de serem vividas, quer pela realidade ou pela atitude consciente. Esta expressão, representação e substituição possibilitam a mediação entre os opostos e elementos separados na experiência do indivíduo, unificando e condensando em uma imagem dotada de sentido e significado a totalidade da experiência humana em todos os seus níveis, isto é, nos campos sociais, cósmicos, religiosos e psíquicos, incluindo a consciência e o inconsciente. Deste modo, ele pode exercer uma função pedagógica e terapêutica, gerando um sentimento e sensação de participação em uma totalidade ou transcendência respondendo às múltiplas necessidades humanas. Esta participação no mundo material e humano acarreta a função socializante do símbolo, pois coloca o indivíduo em comunicação com a totalidade social. Imerso no meio social, ligado à cultura e à experiência individual, o símbolo está vivo e atuante. Nesta atuação e por meio da imaginação, ele é uma forma de relação entre os conteúdos internos, as vivências psíquicas e as percepções do mundo exterior e onde estes se combinam, refletem um ao outro, gerando uma "ressonância" entre si e possibilitando o aprofundamento do indivíduo na experiência pessoal e na vivência em sua totalidade.

Esse processo ocorre no mundo interno do indivíduo, por meio de suas fantasias e imaginação e, muitas vezes, não pode ser percebido objetivamente. Desse modo, ele corre o risco de ser ignorado ou desvalorizado, pois há uma confusão entre a dimensão mítica e a dimensão utilitária do simbolismo, com a dimensão mítica sendo reduzida à utilitária (Durand, 1984). Esse processo de desvalorização epistemológica do imaginário, dos produtos simbólicos e do próprio símbolo vem ocorrendo desde Aristóteles e permeia a racionalidade ocidental desde Descartes. Isto está ligado à identificação do conceito de indivíduo com a razão, "o espírito é pensado segundo as modalidades da experiência objetiva: a res cogitans é considerada segundo o método da res extensa (...) e nisto reside a alienação fundamental." (Durand, 1984, p. 14).

Nesse contexto, o símbolo é reduzido a um signo ou sinal, quando é qualitativamente diferente dos mesmos. O signo é constituído pela fórmula: significado/significante. O símbolo, diferentemente do significante único do signo, possui o significante ao mesmo tempo: a) cósmico: retira sua imagem do mundo ao redor; b) onírico: faz referência a nossas imagens e sentimentos pessoais que se manifestam nos sonhos; c) poético: manifesta-se na linguagem. O seu significado é indizível e não representável, mas aberto. Ele pode ser designado (ter como significante) por qualquer objeto. O símbolo possui uma redundância, isto é, seu significado se manifesta por meio de todos os objetos. Esta repetição (redundância) se realiza ao redor de um centro e possui um caráter de aperfeiçoamento e aproximação, mas nunca alcança o significado, pois este é irrepresentável. Assim o conjunto de todos os símbolos sobre um tema determinado esclarece os próprios símbolos. A redundância simbólica acaba por se manifestar nos rituais e a redundância linguística é significativa dos mitos. A redundância linguística é a repetição de frases, palavras ou uma estrutura que contenha um sentido. $\mathrm{O}$ símbolo pode ser definido como: “(...) signo que remete a um indizível e invisível significado, sendo assim obrigado a encarnar concretamente esta adequação que lhe escapa, pelo jogo das redundâncias míticas, rituais, iconográficas que corrigem e completam inesgotavelmente a inadequação" (Durand, 1998, p. 19).

Desse modo, uma importante manifestação dos símbolos é o mito, pois ele é uma narrativa formada pelo encadeamento das imagens e dos símbolos, abrangendo as narrativas que legitimam as religiões ou cultos, a lenda, o conto popular e a narrativa romanesca. O sentido simbólico dos termos e o encadeamento da narrativa são importantes para o mito. O nível simbólico ou arquetípico é formado sobre a equivalência da forma dentro das estruturas das imagens. O mito "nunca é uma notação que se traduza ou decodifique, mas sim presença semântica e, formado de símbolos, contém compreensivamente seu próprio sentido" (Durand, 1997, p. 357), reduzir o mito ao semiológico (terreno do signo) é empobrecê-lo, pois o mito está no terreno semântico (do símbolo).

O mito é um início de racionalização da experiência simbólica na forma de narrativa, exprimindo um esquema ou um conjunto deles, na qual os símbolos traduzem-se em palavras e os arquétipos em idéias, conceitos, esquemas de pensamento e visões racionais do mundo. Este fato, o mito estar relacionado com a origem da racionalidade, e sendo o pensamento lógico um atributo do ego, costuma-se identificar a consciência mítica com o uma fase do processo de constituição da consciência egóica.

No entendimento da Psicologia Analítica, na origem do psiquismo consciente, existe um estado de identidade e fusão entre o consciente e o inconsciente, estando ambos ligados e inseparáveis. Existe um estado de participação mítica (participation mistyque), isto é, um modo pré-lógico no qual não haveria uma distinção sentida entre o sujeito e objeto e o pensamento estaria sujeito aos afetos e a influência dos objetos externos. Esse conceito foi formulado inicialmente por Lévy-Bruhl (1857-1939) na sua obra Les fonctions mentales dans les sociétés inférieures de 1910. Assim, a participação mítica seria o estado inicial da psique humana na criança, um estado de identidade original, cuja superação seria fundamental para 
qualquer processo de desenvolvimento psicológico, mas que se traduz fenomenologicamente por uma percepção de ligação com os objetos, de participação no mundo, ou seja, o mundo aparece encantado com magia e pleno de significados e com "alma".

Assim, o mito, tal como é conceituado pela Psicologia Analítica e pelos antropólogos e estudiosos da religião como Joseph Campbell $(1992,1990)$ e Mircea Eliade (1977, 1991) não é uma fuga da realidade, uma fantasia ou fabulação primitiva, mas uma realidade viva e uma forma de se colocar e de atribuir sentido ao mundo e que permanece atuante no mundo moderno (Serbena, 1999). Ele satisfaz as necessidades simbólicas e de significado da psique e atua como pano de fundo no sendo comum e no conhecimento científico, especialmente nas ciências humanas e do senso comum (Gusdorf, 1953/1980; Serbena \& Raffaelli, 2003). Inclusive pode-se falar de uma consciência constituída a partir do mito, a consciência mítica.

Nesse sentido diferencia-se consciência mítica como uma forma de ser no mundo e uma experiência específica da realidade - a experiência mítica (Gusdorf, 1953/1980). Esse fenômeno psicológico aparece também na conceituação psicanalítica mais moderna com o termo "identificação projetiva”, descrevendo um processo em que o sujeito projeta uma parte de sua personalidade em um objeto externo que então é experimentado como uma parte de si ou como o conteúdo projetado (Samuels, Shorter \& Plaut, 1988). A identidade não deve ser confundida com identificação, pois ela é um processo inconsciente, no qual o indivíduo não toma ciência do fato dele e do objeto serem separados e age como se existisse uma ligação, como se fossem inseparáveis. A identificação é uma imitação, inconsciente ou não, de uma pessoa ou objeto, na qual o indivíduo reconhece a separação entre ele e o objeto e, por consequência, ele não se percebe idêntico ao objeto; a identificação é um processo normal (Whitmont, 1991).

Em termos da dinâmica da psique, o símbolo, e por consequência os processos simbólicos relacionados ao mito, possibilitam a circulação de energia psíquica através do meio externo, do consciente e do inconsciente atuando em um dinamismo integrador, estabelecendo conexões entre forças psíquicas e objetos opostos e antagônicos. Deste modo, ele opera como uma função transcendente, pois por seu intermédio ocorre uma transcendência ou superação destas oposições e conflitos pela transformação dos seus conteúdos e da energia psíquica que estava retida neles.

O símbolo, a imaginação simbólica e seu dinamismo possibilitam, então, uma diferenciação e desenvolvimento da consciência pela integração dos opostos em direção a uma totalidade (Chevalier \& Gheerbrant, 1989, p. XIX) e uma integração com o mundo que já existia no início do desenvolvimento do psiquismo individual e no contato vital com o inconsciente. Deste modo, o Iluminismo e o pensamento moderno, ao eliminar o transcendente do mundo, efetua - como descreve tão bem Nietszche
- a morte de Deus, transformando o dinamismo vivo e integrador do símbolo do processo lógico e instrumental do signo, intensificando a ação do homem no mundo, mas banindo o encantamento do mundo e perdendo a sua "alma".

\section{Referências}

Campbell, J. (1990). O Poder do mito. São Paulo: Palas Atena.

Campbell, J. (1992). As Máscaras de deus: mitologia primitiva. São Paulo: Palas Athena.

Chevalier, J., \& Gheerbrant, A. (1989). Dicionário de símbolos. Rio de Janeiro: José Olympio.

Durand, G. (1984). Exploração do imaginário. Em D. P. R. Pita (Org.), O Imaginário e a simbologia da passagem (p. 35-42). Recife: Massangana.

Durand, G. (1997). Estruturas Antropológicas do Imaginário. São Paulo: Martins Fontes.

Durand, G. (1998). A Imaginação simbólica. São Paulo: Cultrix e EDUSP.

Eliade, M. (1977). Tratado da história das religiões. Lisboa: Ed. Cosmos.

Eliade, M. (1991). Mito e Realidade. São Paulo: Perspectiva.

Gusdorf, G. (1980). Mito e Metafísica: introdução a filosofia. São Paulo: Convívio. (Originalmente publicado em 1953).

Hillman, J. (1981). Estudos de psicologia arquetípica. Rio de Janeiro: Achiamé.

Hillman, J. (1992). Psicologia arquetípica. São Paulo: Cultrix.

Jung, C. G. (1985a). A Energia psíquica. Petrópolis: Vozes. (Originalmente publicado em 1927).

Jung, C. G. (1985b). Mysterium coniuntionis. Petrópolis: Vozes. (Originalmente publicado em 1954).

Jung, C. G. (1985c). Prática da psicoterapia. Petrópolis: Vozes. (Originalmente publicado em 1957).

Jung, C. G. (1986). Símbolos da transformação. Petrópolis: Vozes. (Originalmente publicado em 1924).

Jung, C. G. (1988). Aion: estudos sobre o simbolismo do Si-mesmo. Petrópolis: Vozes. (Originalmente publicado em 1950).

Jung, C. G. (1991). Tipos Psicológicos. Petrópolis: Vozes. (Originalmente publicado em 1949).

Jung. C. G. (2000). Arquétipos e o inconsciente coletivo. Petrópolis: Vozes. (Originalmente publicado em 1951).

Lévy-Bruhl, L. (1910). Les Fonctions Mentales dans les Sociétés Inférieures. PUF, Paris.

Maffesoli, M. (2003). O Instante eterno: o retorno do trágico nas sociedades pós-modernas. São Paulo: Zouk. 
Maffesoli, M. (2004). Parte do diabo: resumo da subversão pósmoderna. Rio de Janeiro: Record.

Samuels, A., Shorter, B., \& Plaut, F. (1988). Dicionário crítico de análise junguiana. Rio de Janeiro: Imago.

Serbena, C. A \& Raffaelli, R. (2003). Psicologia como disciplina científica e discurso sobre a alma: problemas epistemológicos e ideológicos. Psicologia em Estudo (Maringá), 8(1), 31-37.

Serbena, C. A. (1999). Temas arquetípicos nas histórias em quadrinhos do Batman. Dissertação de Mestrado em Psicologia, Universidade Federal de Santa Catarina, Florianópolis.

Whitmont, E. (1991). A Busca do símbolo: conceitos básicos de psicologia analítica. São Paulo: Cultrix.

Carlos Augusto Serbena - Possui graduação em Engenharia Elétrica e em Psicologia pela Universidade Federal do Paraná, Mestrado em Psicologia pela Universidade Federal de Santa Catarina e Doutorado Interdisciplinar em Ciências Humanas pela Universidade Federal de Santa Catarina. É Professor Adjunto da Universidade Federal do Paraná. Endereço Institucional: Departamento de Psicologia (Universidade Federal do Paraná), Praça Santos Andrade, $\mathrm{n}^{0}$ 50, sala 215 (Ala Alfredo Buffren). CEP 80.060.240 - Curitiba, PR. Email: caserbena@yahoo.com

Recebido em 25.06.09 Primeira Decisão Editorial em 12.09.09 Aceito em 20.12.09 